\title{
A Financial Assets and Liabilities Management Support System
}

\author{
Yung-Hsin Wang \\ Tatung University \\ E-Mail: ywang@ttu.edu.tw \\ Ta-Hua Kuo \\ Formosa Plastics Group \\ E-Mail: allankuo@fpg.com.tw
}

\begin{abstract}
This paper describes the design and implementation of a decision support system (DSS) based on the fund dispatching decision viewpoint from the financial division of a business group. An integrated data warehouse is established and the technique of online analytical processing (OLAP) is applied to analyze daily transaction data of an enterprise resource planning system with determined management goal. We adopt the Business Dimensional Lifecycle approach to accomplish the system design and development. The DSS system developed is to provide latest and timely information of financial asset and liability positions in each company within the case business group so that decision makers can have a clear decision support in fund dispatching. While most related researches on fund dispatching focused especially on efficient banking capital management and few studies were done for general financial department of traditional enterprise let alone for the business group, this study has made a progress in this issue and the resultant system is applicable to the similar business group.
\end{abstract}

Keywords: Financial Asset and Liability, Fund Dispatching, Decision Support Systems, OLAP, Data Warehouse

\section{INTRODUCTION}

The funds is the root of an enterprise, whether an enterprise can run in sustainability lies in its sufficient capability in raising funds as well as the effective management of such funds. If an enterprise can raise all its funds at a much lower cost 
within short time and be able to effectively utilize the funds so that higher investment return is obtained, this enterprise will be more competitive. The funds of an enterprise primarily consists of long-term ones and short-term ones, where the former includes long-term loans, corporate bonds, shares and overseas convertible corporate bonds, etc., and the latter includes the accounts receivable, notes receivable, short-term credit loans and the issuing commercial papers, etc. All these funds are required to repay the principal along with an interest except the shareholding. The short-term fund is more flexible with a lower cost but has a larger pressure of repaying the principal and interest since the due date is shorter. Relatively, the long-term fund costs higher and has longer due date, which allows an enterprise to repay the principal and interest with a much calmer attitude. As for the funding source and allocation, in principle, the short-term funding needs should be paid with a short-term fund, e.g., payment made for the usual items and the short-term interests, while the long-term funding needs should be disbursed with a long-term fund, e.g., the expenditures of principal and interests on loans for expanding the factory's facilities and the corporate bonds. In short, it is extremely critical for an enterprise to have a good fund dispatching and utilization during its business process.

Considering the importance and complexity of fund dispatching decision, the daily routine transaction processing system is certainly incapable of providing people in charge of fund dispatching with more effective management information in time. In order to meet the requirement of instant and accurate decision information upon fund dispatching, it is necessary for an enterprise to design and develop one financial assets and liabilities management decision support system according to the requirements in actual operation which is beneficial for fund dispatching department to respond the changeable external environment.

The primary function of a traditional online transaction system is to record usual transaction activities of an enterprise, assisting in monitoring/controlling internal operational process. Thus its design emphasis is on dealing with huge volume of data entry and data update, the accuracy of data operation, and the efficiency enhancement for data input instead of the functions of online instant analysis and report generation. Ponniah (2001) addressed that the strategic information is acquired by IT personnel directly from the operational database, and such information acquisition usually takes about $4 \sim 6$ weeks once the needs is made by the user. Even worse, the uncertain user requirement or cross-multiplatform data access is likely to directly or indirectly affect the time effectiveness and quality in data acquisition. 
In light of the present prosperous development of information technology, it is quite easy for an enterprise to obtain data from internal operational database, even the external data such as that among industries. However, supposing there is no any real-time, integral and accurate information, a thorough decision can hardly be made to solve the problem or grasp the best possible opportunity when facing the changeable and competitive environment. The current trend is to construct a system with business intelligence (BI) to assist the executives in promoting the enterprise managerial performance by rapidly acquiring, analyzing and inducing useful information among different sources of databases (Liang, 2006).

With the introduction of BI, the enterprise would be able to acquire, summarize and analyze a great deal of data from various sources, and then present the results with tables and illustrations, which are not only applicable to the high-level management but also extensible and accessible to the managers of any level, thereby construct an Enterprise Information System (EIS) (Turban, Aronson \& Liang 2005). In the EIS, including BI, aside from the pre-offered query mechanism, users are even allowed to design their own analysis means to enhance system flexibility without excessive effort and significantly shorten the time in acquiring the analysis results. In addition to decision-making support, the system can also monitor and control the anomaly, assist in exception management, and evaluate the enterprise's performance, even predict future trend with what-if analysis (Lin, 2005).

This study based on the concept of BI shall analyze the routine transaction data in an Enterprise Resource Planning (ERP) system with the defined management goal to construct a decision support system for fund dispatching. We utilize Microsoft SQL Server 2005 to establish the data warehouse and utilize Strategy Companion Analyzer 2005 (hereinafter referred to as Analyzer 2005) in data processing and interface design so as to provide users with an explicit analysis result of variations on the financial assets and liabilities risk where the decision-makers will have a timely assistance in making appropriate decisions in accordance with future funds demand.

Our study case is one domestic business group which consists of 47 sub-companies with a total turnover in 2005 over 30 billion US dollars. All funds for the entire group are allocated in unification by the financial department with the purpose of effectively using all the resources. Therefore, the financial department has to master at any time the daily flow information of financial asset and liability position of each company in the group, so that it is able to properly respond daily funds demand for the enterprise, and allocate as a whole the funds according to the market circumstances. In addition, all available funds should reasonably support each other. 
Besides gathering the latest market information, the most important issue for the persons who are managing the fund dispatching is to precisely control the remaining/insufficient balance positions of cash flow in order to make instant decisions for fund dispatching. However, the current fund dispatching information system used by the case business group is mainly in support of usual management and routine transactions processing, so it is necessary to use additional tool such as Excel to design customized management lists if someone would like to examine the data from various viewpoints or the aggregated data. Therefore, the development of the financial assets and liabilities management decision support system for the business group would facilitate the financial persons in controlling deposit/loan position information of each company to rapidly react the chargeable financial markets.

In the rest of this paper, we shall have a brief review of the related techniques used in our DSS/BI and an overview of the financial assets and liabilities management. We then explicate in details the design and realization for the DSS system of this study. System demonstration according to the management indicators and some decision analysis patterns will be presented.

\section{BRIEF REVIEW OF RELATED TECHNIQUES}

A business intelligence system primarily consists of the following (Liang, 2006): (a) the tool for extracting, transforming, and loading (the ETL process) daily routine transaction data into data warehouse; (b) the data warehouse subsystem which will save all data in a multi-dimensional way according to various subject of information; In short, this is a database particularly for supporting the decision-making; and (c) the front-end business intelligence tool or platform, e.g., the online analysis or balanced scorecard, which is mainly offered to the decision makers of an enterprise to access, analyze, and share the information saved in data warehouse. It can be used as one of the tools available or can act as the basis in developing application software, and then further developed into some specific analytical application software according to different requirements.

Inmon (2005) defined four primary features for the data warehouse: (1) Subject oriented: The data warehouse performs all related analysis based on various subjects. For instance, the related subjects used in the financial data warehouse might be the client, interest rate, deposit and loan balances, etc.; (2) Integrated: The data warehouse has various data sources, which has been cleansed and integrated before being saved into the system; (3) Nonvolatile: The major data saved in the data warehouse is extracted from the historical transaction processing database, and hence all data 
loaded into the data warehouse system is read-only, which means there won't be any operation of adding, deleting, or updating; and (4) Time variant: All data saved in the data warehouse is somehow time-related.

In sum, the data warehouse could be defined as a kind of infrastructure for integrating all data of an enterprise according to each particular subject, wherein all data are further processed via tools like online analysis and data mining to provide decision makers with rapid, integrated, visualized and analytical information. The data warehouse system used for the financial assets and liabilities DSS of this study is built on the SQL Server 2005, where all related data is firstly extracted, integrated, transformed and loaded into the data warehouse, and then a dimensional database is designed with Analysis Services for online analysis.

The primary analysis method used in Online Analytical Processing (OLAP) comprises: (a) drill-down - used typically in one-dimensional or one layer, in which data is analyzed from high layer toward low layer; (b) roll-up - used typically in one-dimensional or one layer, in which data is analyzed from low layer toward high layer; and (c) cross-dimensional drilling - cross different dimensions to do analysis (Liang, 2006).

This study utilizes the features and advantages of Analyzer 2005 that allows an enterprise to define their business entity, business logic, and computing formulas as the measuring information related to reports, work sheets, OLAP browser, and KPIs, etc. The tool is used to assist all fund dispatching personnel and staffs working in financial department in designing the necessary dynamic reports and graphics analysis along with the warning function suitable for making the financial assets and liabilities management decisions.

\section{FINANCIAL ASSETS AND LIABILITIES MANAGEMENT}

Some researches on financial assets and liabilities management are about the financial (banking) industry (Hung, 2001; Liu, 2003; Peng, 1994); few were done for general financial department of non-financial industry. In what follows we proceed to have a review of financial assets and liabilities and their risk management.

\section{Financial Assets and Liabilities}

The most popular finance investment objects are financial instruments, where the so-called financial instrument means any contract that gives rise to both a financial asset of one enterprise and a financial liability or equity instrument of another enterprise (KPMG, 2004). A financial asset is any asset that is: (a) cash; (b) a 
contractual right to receive cash or another financial asset (e.g., account receivable, loan, and debt investment) from another enterprise; (c) a contractual right to exchange financial instruments (e.g., derivatives such as financial options and forwards, including futures, as well as interest rate swaps and currency swaps) with another enterprise under conditions that are potentially favorable; or (d) an equity instrument (e.g., shares) of another enterprise. A financial liability is any liability that is a contractual obligation: (a) to deliver cash or another financial asset (e.g., account payable, debt, and issued bonds) to another enterprise; or (b) to exchange financial instruments with another enterprise under conditions that are potentially unfavorable (Cheng, 2004).

As has been indicated, this study aims at analyzing the financial assets and liabilities position for the financial department of the case business group and providing the business intelligence tool for supporting fund dispatching decision-making, in order to perform the risk management while responding any time to variation conditions in the macroeconomic market.

\section{Risk Management}

Risk can be viewed as uncertainty in cash flows which influences the fair value of recognized assets and liabilities or the level of cash flows relating to future transactions (KPMG, 2004). The financial risks that are related to financial instruments include: interest rate risk, currency risk (also referred to as foreign exchange rate risk), market risk (also referred to as commodity or price risk), credit risk, and liquidity risk. Other risk sources include many non-economic factors, such as the political factor (Shieh, 2006). A common strategy in risk management is hedging, where risks that an entity faces are reduced or eliminated by entering into transactions that give an offsetting risk profile (KPMG, 2004). The most importance of risk management is the control of the risk exposure level, which is trying to utilize a simple quantified analytical method to grasp the potential risks on the financial assets or liabilities in order to respond with a necessary measure. Two kinds of risk factors that highly affect the financial assets and liabilities are the interest rate risk and the currency risk. The interest rate risk represents the risk that future changes in prevailing interest rates will affect the fair value or cash flows of a financial right or obligation. Changes in market interest rates may affect an entity's right to receive or obligation to pay cash or another financial instrument at a future date, or the fair value of that right or obligation. The currency risk is the risk that changes in foreign exchange rates will affect the fair value or cash flows of a recognized financial instrument, firm 
commitment or forecasted transaction. Thus, the fluctuation in both the interest rate and exchange rate will result in an uncertainty of future cash flow related to the financial assets and liabilities.

In light of above description, according to the condition of each company's foreign exchange demand and funds balance, the financial division of the case group should go with market direction to make a good short-term, mid-term and long-term hedging strategy as well as choose the most suitable financial product. When the foreign exchange fund is insufficient, they have to make spot exchange or forward transaction based on a favorable market rate. On the aspect of long-term foreign currency liability, they can contract cross currency swap (CCS) transaction with several international well-known banks, when the swap rate or swap point is beneficial for them. The purpose is to reduce the effect on the profit that exchange rate fluctuation incurred. As for the long-term liabilities with floating rate, to hedge the interest rate risk, they can evaluate circumspectly the status of financial market to contract interest rate swap (IRS) with several international well-known banks, when the interest rate is low.

In a word, authentically grasp the position of financial asset and liability and evaluate the risk of short-term or long-term position based on the market price, the business group can then control the circumstance of profit and loss on exchange of each company's risk position, and insure the performance of hedging trading.

\section{SYSTEM DESIGN AND IMPLEMENTATION}

This study primarily aims at developing the DSS system based on the practical requirements for the financial department of the case group. The MIS system used for routine operations inside the group is developed in unification by the information department. The group's ERP system mainly consists of six principal management functions: the financial management, business management, personnel management, production management, material management and engineering management.

\section{Fund Dispatching System for the Case Group}

Among the operations in the ERP system, the fund dispatching management system belongs to the financial management computer operation. The design of fund dispatching operations is mainly for daily operational fund dispatching requirements, including the investment needs of time deposit, short-term commercial papers, funds and bonds, as well as the margin loan needs, such as short-term loans, issued commercial papers, long-term loans, corporate bonds, etc. 
There are two main management information systems: NT Dollar fund dispatching system, and foreign currencies fund dispatching system. The NT Dollar fund dispatching system contains operations for quota management, co-allocation among companies, deposit input, reports of due bills, and due bills reminder, etc. The foreign currencies fund dispatching includes various setting and reports for the short-term credit loans of foreign currencies, foreign currency temporary loans, and foreign currencies trading as well as due presentation, etc. Since revenue and expenditure data required for daily fund dispatching belongs to the cashier system, it will be transferred automatically to the cashier MIS system, so as to perform daily collection and payment operations. After that the cashier MIS will draw the daily revenue and disbursement slips which are then transferred into the accounting MIS for subsequent accounting process, as shown in Figure 1.

This study aims at constructing an enterprise intelligence system to support the financial department in fund dispatching decisions. Thus, the operational data used in the case group's fund dispatching computer operations is acting as an original internal data source of this study. In addition to the original internal data, being extracted, processed, transformed, and then loaded into the data warehouse system, data related to the external interest rate and exchange rate will be brought in simultaneously as the critical indicators of the system being developed.

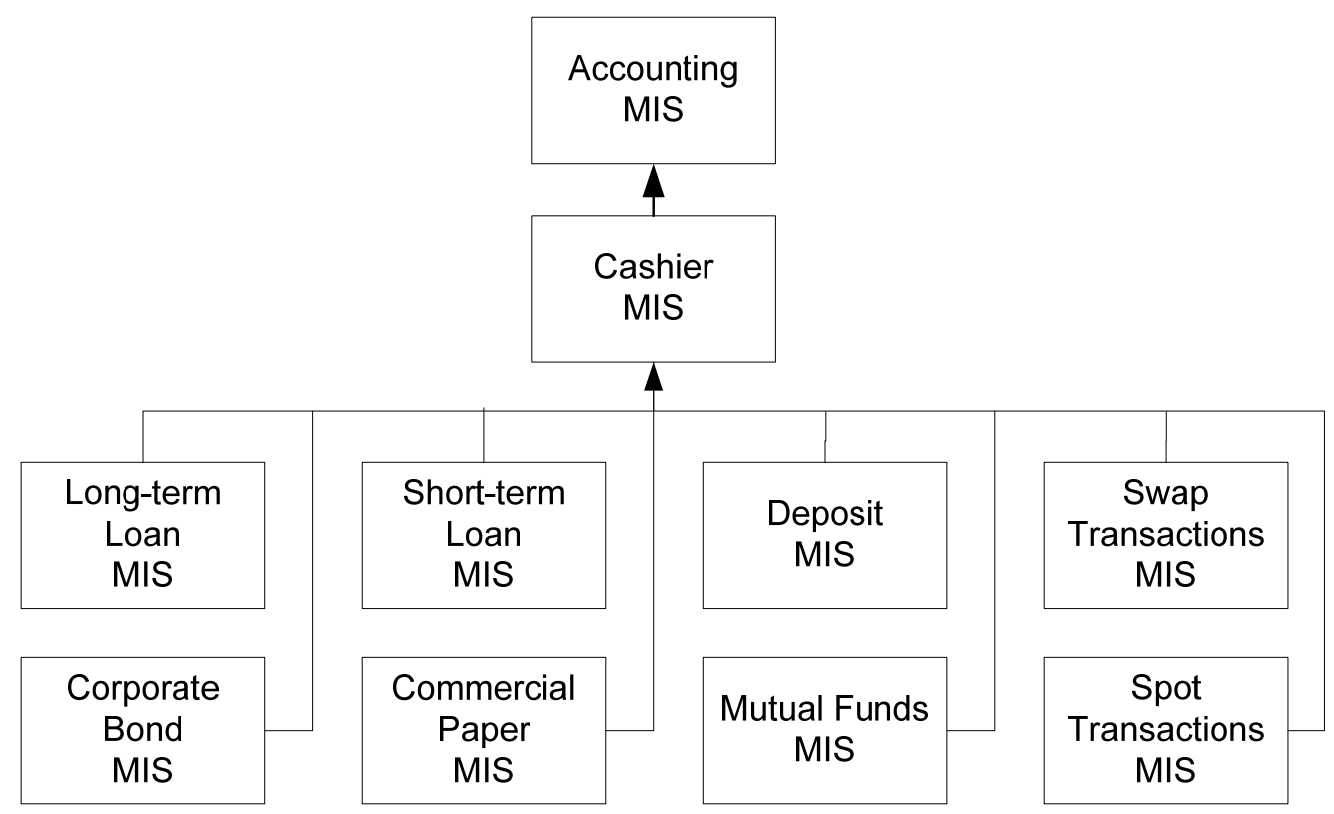

Figure 1 The Operations of Fund Dispatching System for the Case Group 


\section{System Design and Development}

The system design and development process of this study follows the Business Dimensional Lifecycle approach (Kimball, Reeves, Ross, \& Thornthwaite, 1998; Mundy, Thornthwaite, \& Kimball, 2006). As Figure 2 illustrates, the Business Requirements Definition is the foundation of the Lifecycle methodology. It also influences the project plan, hence the arrow pointing back to the Project Planning box. Business requirements and their associated business value provide the guidance you need to make decisions in all three downstream tracks: the top track is about technology, the middle track is about data, and the bottom track is about business intelligence applications. The tracks combine when it is time to deploy the system. Maintaining the system doesn't begin after deployment. The growth phase of the project linking to the arrow heads back to the beginning. The Project Management across the entire Lifecycle controls the project development. The Lifecycle's incremental approach is a fundamental element of delivering business value. We now proceed to describe each phase of this study in what follows.

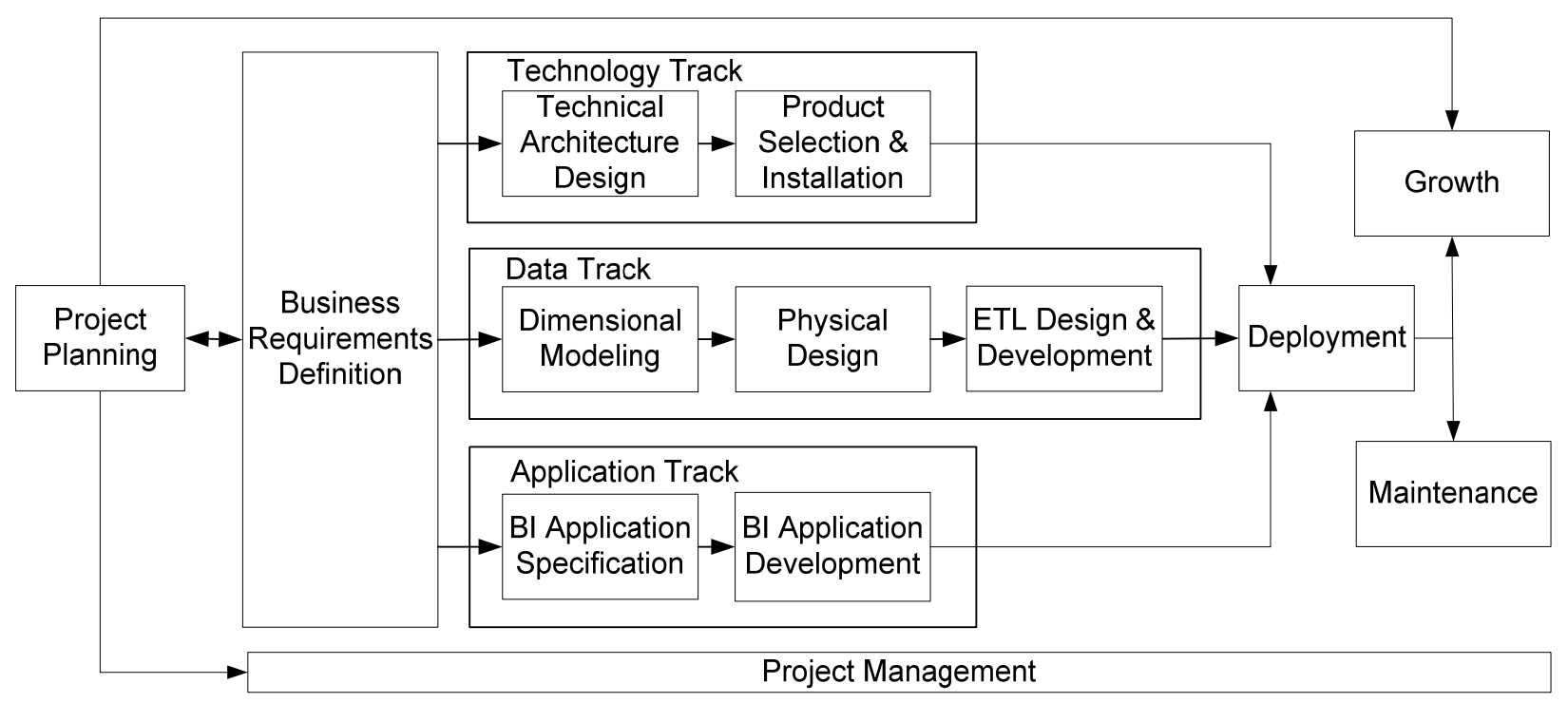

Figure 2 The Business Dimensional Lifecycle

\section{Project Planning}

Both the objectives and scope of the data warehouse project conducted by the enterprise should be revealed in this phase, including the readiness assessment along with the business justification for the data warehouse implementation. This study attempts to create a system with simple and flexible user interface for fund dispatching personnel of the financial department, whereat they can adjust the analysis view individually based on their decision needs whenever necessary. Moreover, the 
system should provide the latest information related to financial asset and liability positions, as well as various risk management performance indicators for daily use. All relative information should be presented in visualization; meanwhile the staffs in financial department should be allowed to have an in-depth investigation based on various chart data so as to immediately control the cause and effect of each kind of information together with that of the anomaly. In this way, they will be able to work out countermeasures and strategies together with fund dispatching personnel in the financial department against various situations.

\section{Defining Business Requirements}

As the foundation of the Lifecycle, specifically understand and define the business needs is critical. After discussed with the leaders of foreign exchange trading division and risk management division in the financial department of the group, we found that there is a need to clarify the contents of primary requirements as follows:

- Providing dynamic reports of financial asset and liability positions of each company everyday, so that the fund dispatching personnel would be able to control the position status all the time.

- Providing dynamic reports of financial asset and liability positions of each company everyday with separate due date, so that the fund dispatching personnel would be able to control the position status of future due date all the time.

- Reports must present the average exchange rate as well as weighted average interest rate for each financial asset and liability position.

- Reports must be able to reveal the detailed information of each case at any time which is favorable to the presentation of instant response strategies.

\section{Dimensional Modeling}

Designing the dimensional model falls within the central section of the Lifecycle which focuses on data. The main objective is to make sure users get the data they need to meet ongoing business requirements. The goal in this step is to create a usable, flexible, extensible data model. To create the data model in this study, various transaction data used in the said fund dispatching system would be typically classified as several principal subjects, such as the short-term investment, long-term investment, short-term loans, long-term loans, and derivatives, etc., and then the level of detail of fact data will be settled afterward. To allow the data warehouse to rapidly drill-down or roll-up via the OLAP analysis function, we define the detail of fact data as follows, based on the information more concerned by the user: 
- Long-term/short-term loans positions analysis for each company in the group

- Long-term/short-term financial assets investment positions analysis for each company in the group

The main dimensions are time, company, and financial instrument (i.e., product) as shown in Table 1.

\section{Physical Design}

The design for the physical architecture based on the previous data models includes the definition of naming scheme, the setting of database environment, initial index and data partition. As shown in Figure 3, there are two data cubes used to store the position data related to the financial assets and liabilities as well as position data of each period respectively.

Table 1 Dimensions and the Fact Data Model

\begin{tabular}{|c|c|c|c|}
\hline Dimension & time & company & $\begin{array}{c}\text { financial } \\
\text { instrument }\end{array}$ \\
\hline Unexpired long-term financial assets position analysis & & $\checkmark$ & $\checkmark$ \\
\hline Unexpired short-term financial assets position analysis & & $\vee$ & $\vee$ \\
\hline Unexpired long-term financial liabilities position analysis & & $\vee$ & $\vee$ \\
\hline Unexpired short-term financial liabilities position analysis & & $\vee$ & $\vee$ \\
\hline $\begin{array}{l}\text { Unexpired long-term financial assets position analysis in } \\
\text { each period }\end{array}$ & $\vee$ & $\vee$ & $\vee$ \\
\hline $\begin{array}{l}\text { Unexpired short-term financial assets position analysis in } \\
\text { each period }\end{array}$ & $\vee$ & $\vee$ & $\vee$ \\
\hline $\begin{array}{l}\text { Unexpired long-term financial loans position analysis in } \\
\text { each period }\end{array}$ & $\vee$ & $\vee$ & $\vee$ \\
\hline $\begin{array}{l}\text { Unexpired short-term financial loans position analysis in } \\
\text { each period }\end{array}$ & $\vee$ & $\vee$ & $\vee$ \\
\hline
\end{tabular}




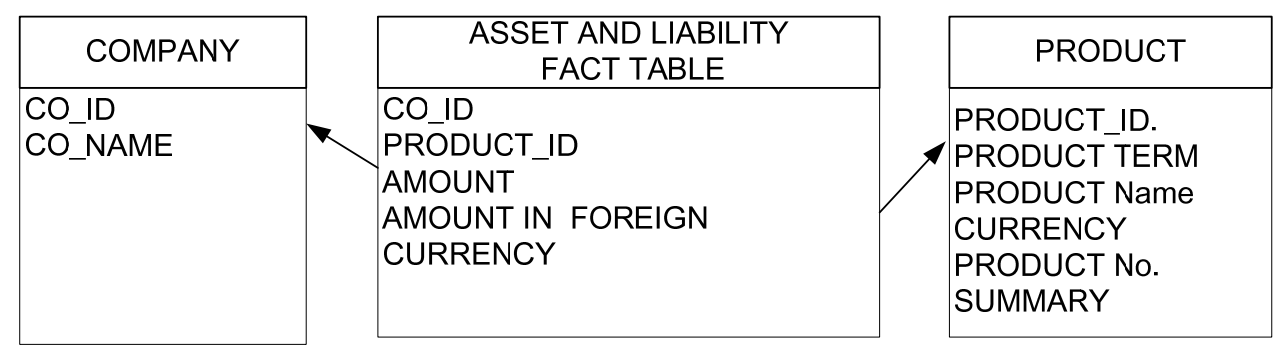

Financial Asset and Liability Star Schema
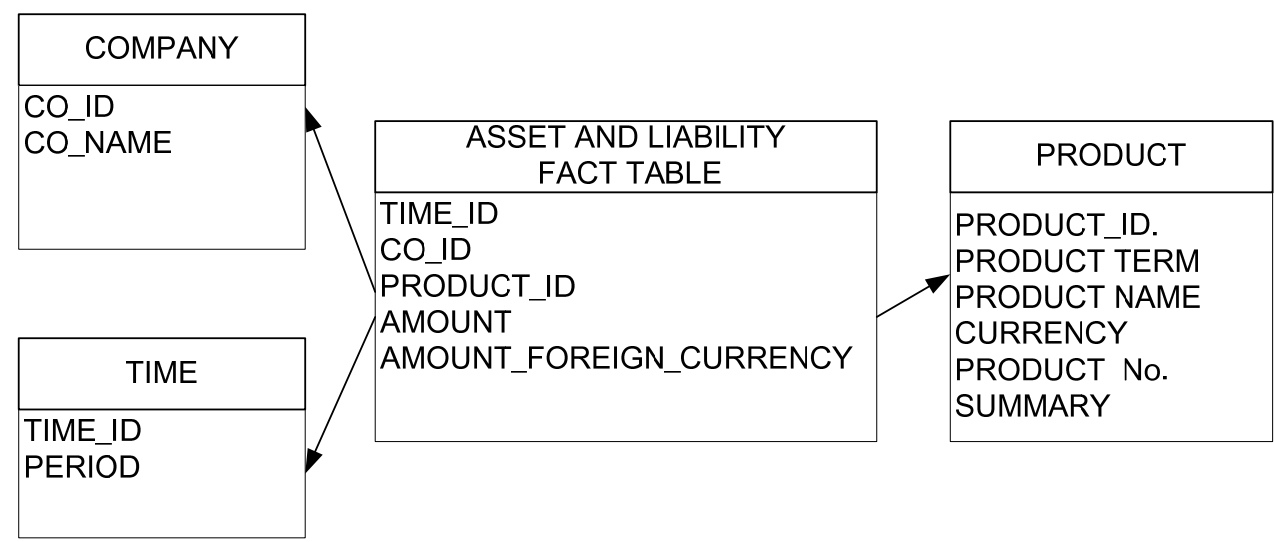

Periodical Financial Asset and Liability Star Schema

Figure 3 The Database Schema of This Study

\section{ETL Design \& Development}

The primary work in this phase is related to the ETL operation, that is, to extract, transform and load the source data to the data warehouse. While extracting the source data, we have to take care of the issue of data quality. It is generally being divided into two different procedures, namely that of the primary data loading operation for the "initial overall historical data" and that of the secondary data loading operation for the "routine increment of partial data." Firstly, this study links the Oracle source database via Ole Db, and then extracts the revenue data, payment data, and financial asset and liability data so as to transfer them to the SQL Server database (T0nfts114). Then, all related data are copied via a SQL program (P0NFW001.SQL), to individual dimension table and fact table according to its property (see Figure 4).

As to the OLAP Cube design, two cubes were created based on the two schemas (see Figure 3) of the database physical design. The financial asset and liability cube comprises a "company" dimension (T0NFCU01), a "product” dimension (T0NFCU03) and a fact table (TONFCU05). Aside from the two dimensions the other cube adds one "time" dimension; the purpose is to let users know the expired financial asset and liability positions in each period in order to consider investing another product for the due asset, while consider paying off the liability earlier or hedging earlier. 


\section{Technical Architecture Design}

As Figure 5 illustrated, the system architecture of this study comprises three main layers: the operational data store layer, the data warehouse layer, and the front-end application layer, and is described in what follows:

- The operational data store layer is primarily storing up the daily routine transaction data with the fund dispatching department of the enterprise. Considering the necessity for cleansing and integrating daily routine transaction data before loading into the data warehouse, which will consume a great deal of system resource, we in this study separate the general operational system from the data warehouse, in order to prevent all transactions and analysis operations being processed on the same server.

- In the data warehouse layer, there are two major works: one is to extract data from the operational database and then transform and load into the data warehouse system by applying several business rules; the other is to generate analytical data in multi-dimensional way (i.e., the so-called the Data Cube) using the OLAP technique.

- The front-end application layer provides a user-friendly operating environment by means of the OLAP client-end interface. In addition, present to the user with analysis charts, table or texts. Thus, it is very easy for the decision-makers to acquire all necessary data via the front-end tools.

\section{Product Selection \& Installation}

Considering an integrated business intelligence tool, this study has selected and utilized Windows SQL Server 2005 to build the data warehouse system, including data transformation and data dimension design. The Integration Services and Analysis Services provide rather user-friendly developing interface for data extraction and cube design. In addition, the Analyzer 2005 with its visualized and intuitive operation interface is also chosen as the tool for designing the front-end interface of our DSS/BI system.

\section{BI Application Specification}

The planning of the business intelligence application in this study is mainly based on the financial assets and liabilities data, which has been classified into current position data and future expired position data in each period of each company. On the interface design, visualized charts will help decision-makers control both the daily funds position and future liability position data in a much clearer and quicker way. As to the application programming design, the relative users have been classified into the system administrator, report designer and front-end user; the authority level is specified according to their 
distinct roles. The system administrator is mainly responsible for defining the data source and logic, integrating all internal data within enterprise, defining and creating cubes users required, designing and analyzing all necessary dimensions and measures, examining authority related to source data, as well as configuring the cube and dimension authority for the report designers. The report designer is allowed to create, in accordance with their domain know-how, the analysis reports, graphics and dashboard, and to drag data from the Cube with tools such as Analysis Designer and Report Designer or setup query conditions, etc. The front-end user is, thereby, allowed to use the defined charts and perform interactive functions among charts, such as drill-through and drill-down. In addition, the data content across different Cubes can be presented with a visualized method, such as dashboard, roll-up and drill-down, red and green signal lights, percentage, etc., so that the relative user would be able to rapidly acquire all necessary data with an enhanced working efficiency.

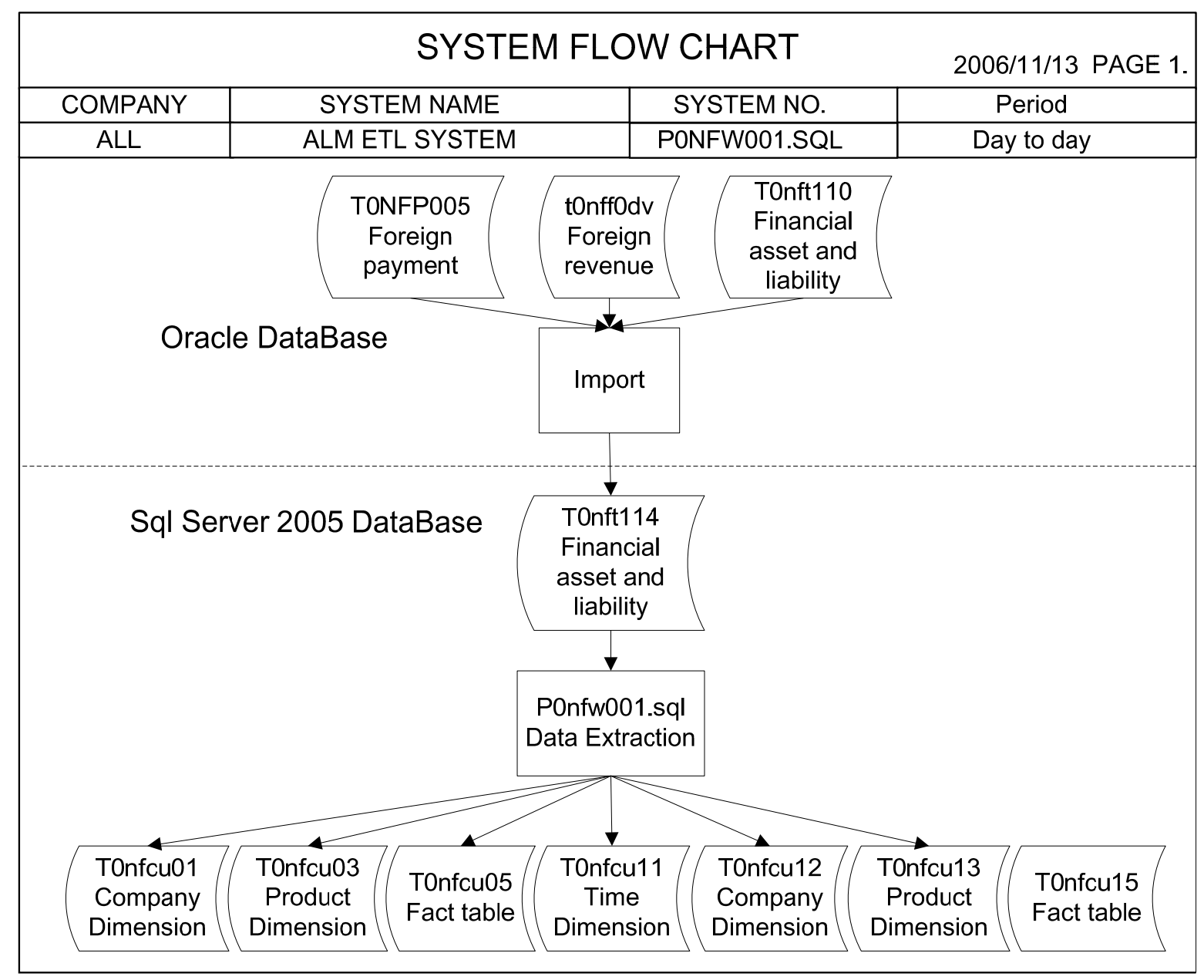

Figure 4 The Financial Asset and Liability Data Extraction and Transfer 


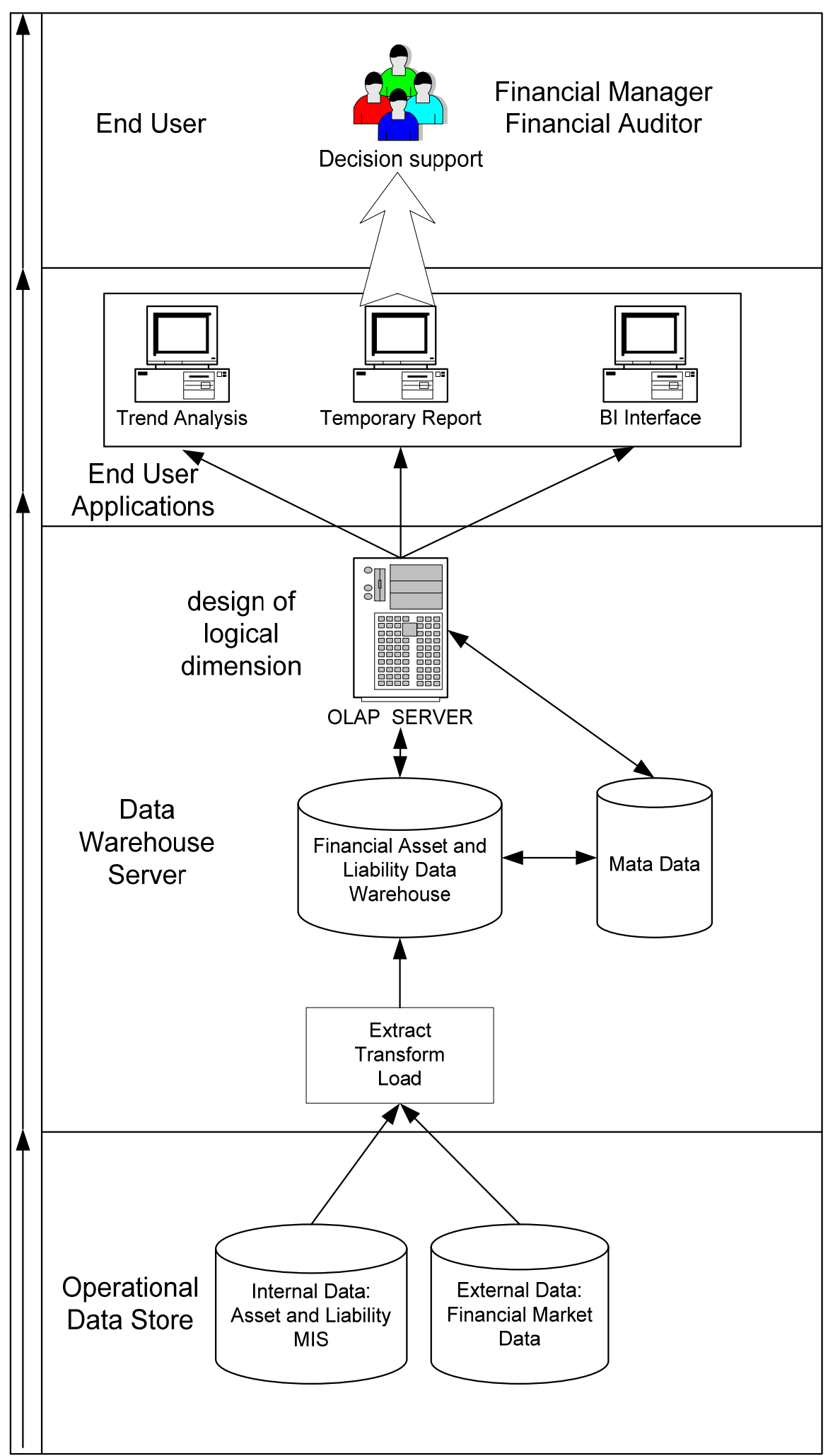

Figure 5 The Architecture of Business Intelligence System for This Study 


\section{BI Application Development}

The primary task in this phase is to accomplish the end-user application programming design via the metadata design and report generation, as well as provide the user with a capability of modifying the report templates. Therefore, reports designed in this study after deployed to the users of different levels, should allow users to interact among various charts and table, and perform the necessary decision management by setting various warning indicators (see Table 2). However, this setting is not decided by the single user; it should be considered in the early project planning to define suitable criteria that meet enterprise's benefit.

Table 2 User-defined Warning Rules

\begin{tabular}{lll}
\hline \multicolumn{1}{c}{ Item } & \multicolumn{1}{c}{ Indicator } & \multicolumn{1}{c}{ Recapitulation } \\
\hline Time deposit & $\begin{array}{l}\text { Equivalent NT Dollars }> \\
50,000,000\end{array}$ & $\begin{array}{l}\text { Time deposits converted to NT } \\
\text { Dollars over fifty million }\end{array}$ \\
\hline Funds & $\begin{array}{l}\text { Each fund's weighted-average net } \\
\text { worth }<\text { (each money market's net } \\
\text { worth + user's own definition } \\
\text { value) }\end{array}$ & $\begin{array}{l}\text { Weighted-average net value } \\
\text { reaches the control threshold }\end{array}$ \\
\hline $\begin{array}{l}\text { Short-term credit } \\
\text { loan in foreign } \\
\text { currencies }\end{array}$ & $\begin{array}{l}\text { Each loan's cost exchange rate }> \\
\text { (market exchange rate + user's } \\
\text { own definition value) }\end{array}$ & $\begin{array}{l}\text { Cost exchange rate reaches the } \\
\text { control threshold }\end{array}$ \\
\hline Long-term loans & $\begin{array}{l}\text { Each loan's interest rate }> \\
\text { (market interest rate }+ \text { user's own } \\
\text { definition value) }\end{array}$ & $\begin{array}{l}\text { Cost interest rate reaches the } \\
\text { control threshold }\end{array}$ \\
\hline $\begin{array}{l}\text { Estimated } \\
\text { financing gap }\end{array}$ & Minus gap & $\begin{array}{l}\text { Predicting via the historical data } \\
\text { where the revenue is less than } \\
\text { the expenditure }\end{array}$ \\
\hline
\end{tabular}

10. Deployment

This phase concerns system deployment. The business intelligence system accomplished will be deployed to each user via the Web. Furthermore, a mechanism of user support, communication, and opinion feedback will be established through a user training program.

\section{Maintenance \& Growth}

As to the design of data transformation scheduling, the current project consists of 12 data transformation service operations in total. The first priority of transformation is the dimension data table, and then each fact table since the fact table contains the primary key of dimension data table; if the fact table were transformed first, it might 
cause a situation that the foreign key cannot be indexed. To extract the latest position data, in our case, the transformation time has been set to 11:00am everyday, so as to comply with the current fund dispatching operation time along with the data conversion of the current market interest rate and exchange rate. Maintenance is a critical task, but it's not the only ongoing effort. Growing the warehouse is really about adding value to the business. The more business information in the warehouse, the more valuable it becomes. The data volume in the warehouse will be increased gradually from time to time; therefore at the initial stage, it is necessary to set up the integrated data backup and archive functions. The appropriate backup time should be selected on a non-working day, e.g., Sunday, so as not to affect daily data conversion.

\section{Project Management}

The project management can ensure that every operation can be proceeded on a fixed schedule in every stage of Business Dimensional Lifecycle. It is performed across all relative activities in the overall lifecycle; in addition to the regular operations, such as the project status monitoring, initializing operation, controlling the project scope, it is able to provide a continuous communication between the information department and the user. Upon completion of the system being studied, if there are new requirements from any relevant department, it can be raised through the case group's office automation system searching for the continuous improvement.

\section{SYSTEM DEMONSTRATION AND DECISION ANALYSIS}

The primary objective of the DSS/BI system for financial assets and liabilities management in this study is to support fund dispatching personnel to make the appropriate management decisions, which is capable of providing with the relevant users the financial statistical figures of each financial asset and liability position, weighted average interest rate of liability position, weighted average exchange rate of foreign currencies position, etc. The following presents the results.

\section{Position Analysis}

Since the financial department of the case enterprise manages the fund dispatching in unification, using the ERP reports they have to do the tedious work of comparison and calculation of those aggregated and detailed forms to know each company's funds status. The position analysis function of our system provides users easy control of the financial asset and liability status. Moreover, they are able to drill-down or roll-up against each product item. Users are free to adjust and execute 
when viewing the entire liability position or the short-term credit loan, company bonds, etc. of liability position. The present system would also allow any relevant user to find out the exact ratio of each company's financial assets and liabilities position to that of the group via analysis charts (as shown in Figure 6). If necessary, the user is able to adjust the measure so that all relevant charts with a specific measure will be adjusted automatically in synchronization. In sum, the position analysis function of this system has increased the efficiency of gathering each company or entire enterprise's financial asset and liability position for the user.

\section{Cash Gap}

Since the case group is one of the traditional manufacturing enterprises, its usual operation is quite stable. So in this study we adopt the historical data of purchase expenses and business revenues to predict future payments in foreign currencies for the fund dispatching personnel to control the future funding needs, and hence conduct in advance the appropriate foreign exchange hedging. We utilize the following models to calculate the historical revenue and expenditure data along with predictions (using mainly average value to modify any inaccuracy caused by significant fluctuation when across months): (a) modify the real income and expenditure data of the particular month in last year, which is equivalent to the month earlier than the current month, with an average value of two months in last year, which are equivalent to the two months earlier than the current month in the same period (referred as the Code A); (b) modify the real income and expenditure data of the particular month in last year, which is equivalent to the exact same month as the current month, with an average value of two months in last year, which are equivalent to the exact same month plus one month earlier than the current month in the same period (referred as the Code B); (c) acquire the fluctuation status of the same period in last year by the calculation of B/A (referred as the Code F); (d) the average real income and expenditure data of the two months earlier than the current month in this year (referred as Code C); and then (e) estimated account receivable and payable data of current month $=\mathrm{C}^{*}(1+\mathrm{F})$.

In Figure 7, “1, 2, 4, 6” at the vertical axis represents the code of each company, and the horizontal axis represents predicted account receivables, account payables, and cash gaps for current month based on each currency and each company. With these tables, the fund dispatching personnel in the financial department will be able to understand the estimated monthly funds gap, and take countermeasures in advance after measuring the market risk. And in this way, the fund dispatching operation will 
be much easier even while the company is required to pay huge amount of funds, since all requirements on usual funds have been taken into account already.

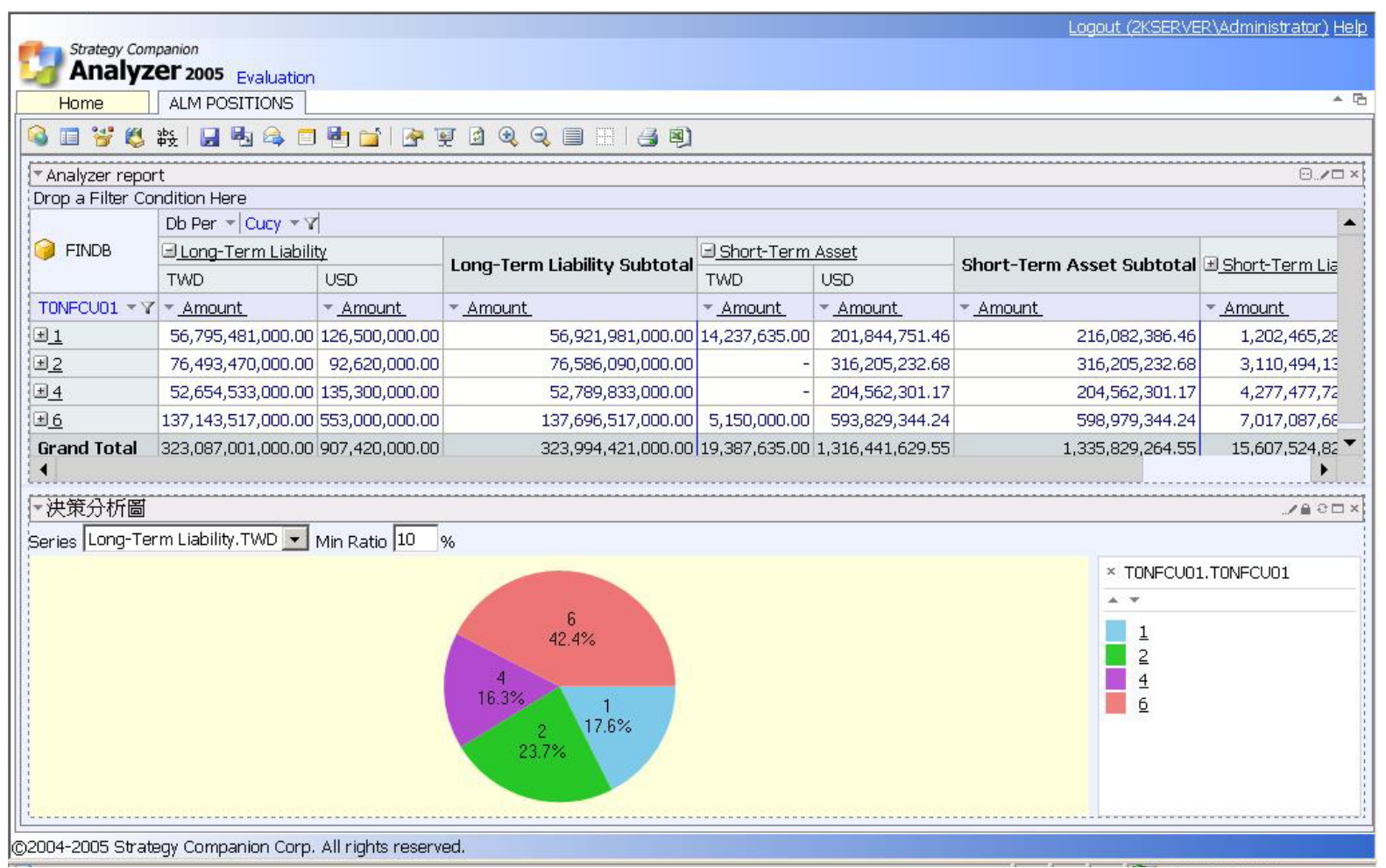

Figure 6 The Financial Assets and Liabilities Position Analysis

\section{The Average Interest Rate and Market Interest Rate}

With the statistics on the financial asset and liability position, it is able to control the various financial asset and liability conditions of each company in the group, and acquire fund cost of each short-term loan position via weighted average interest rate data. Then all relevant data can be provided to the decision-makers of fund dispatching in order to take any necessary countermeasure to keep away all potential risks accordingly. Supposed that the fund dispatching personnel finds the weighted average interest rate of partial liability position is too high, then he will be able to probe into the interest rate data of each case (as shown in Figure 8) by drill-down and make a decision to pay back such loan immediately if the penalty amount of the loan is less than such interest expense. 


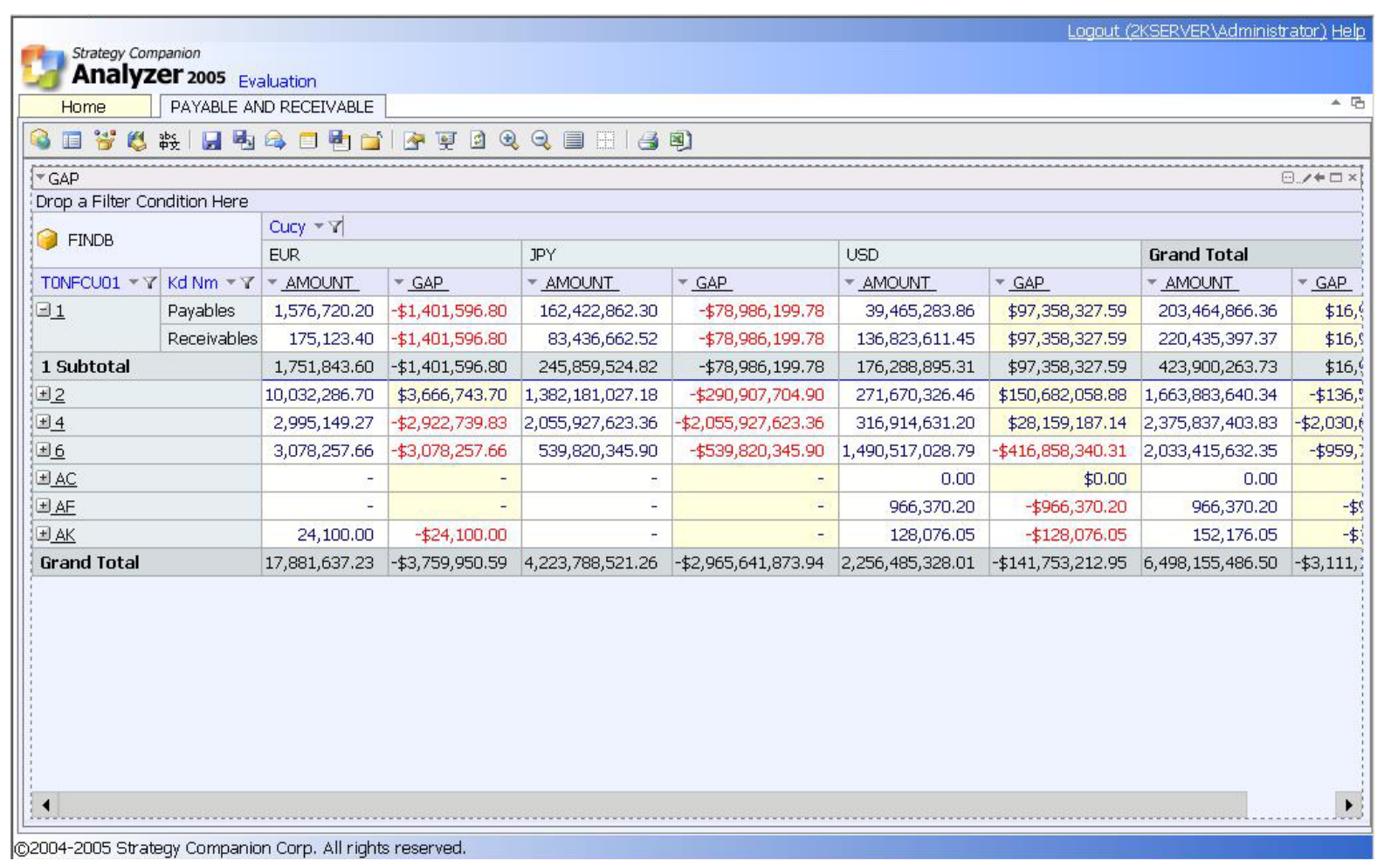

Figure 7 Account Receivable and Payable Data Position Prediction

\section{The Average Exchange Rate and Market Exchange Rate}

With the analytical tools according to our implementation, users can reveal the exchange rate condition of daily liability position (as shown in Figure 9). Moreover, the warning setting function will remind the fund dispatching personnel whether the exchange rate risk of each case is too high or not, or if there is a necessity to make a decision to return such principal or take a countermeasure in advance with available foreign exchange tools.

\section{Position Warnings}

With the warning function on various positions, it is applicable to remind the fund dispatching personnel to take account of the additional investments in other high-yield financial instruments, if the time deposit position has been too high, and not to increase the time deposit position any more. However, the risk management personnel also can find out, while there is a warning, the investment reason for each case of time deposit via drill-down, and then do nothing at all if the said reason is just a kind of assurance. For any investment without any particular intendment, the fund dispatching personnel should be asked to draw up other investment decisions which must facilitate the effective application of the remaining fund position. As can be seen 
in Figure 10, the sum over fifty million dollars is highlighted in red to remind the fund dispatching personnel to investigate the reason for abnormal condition.

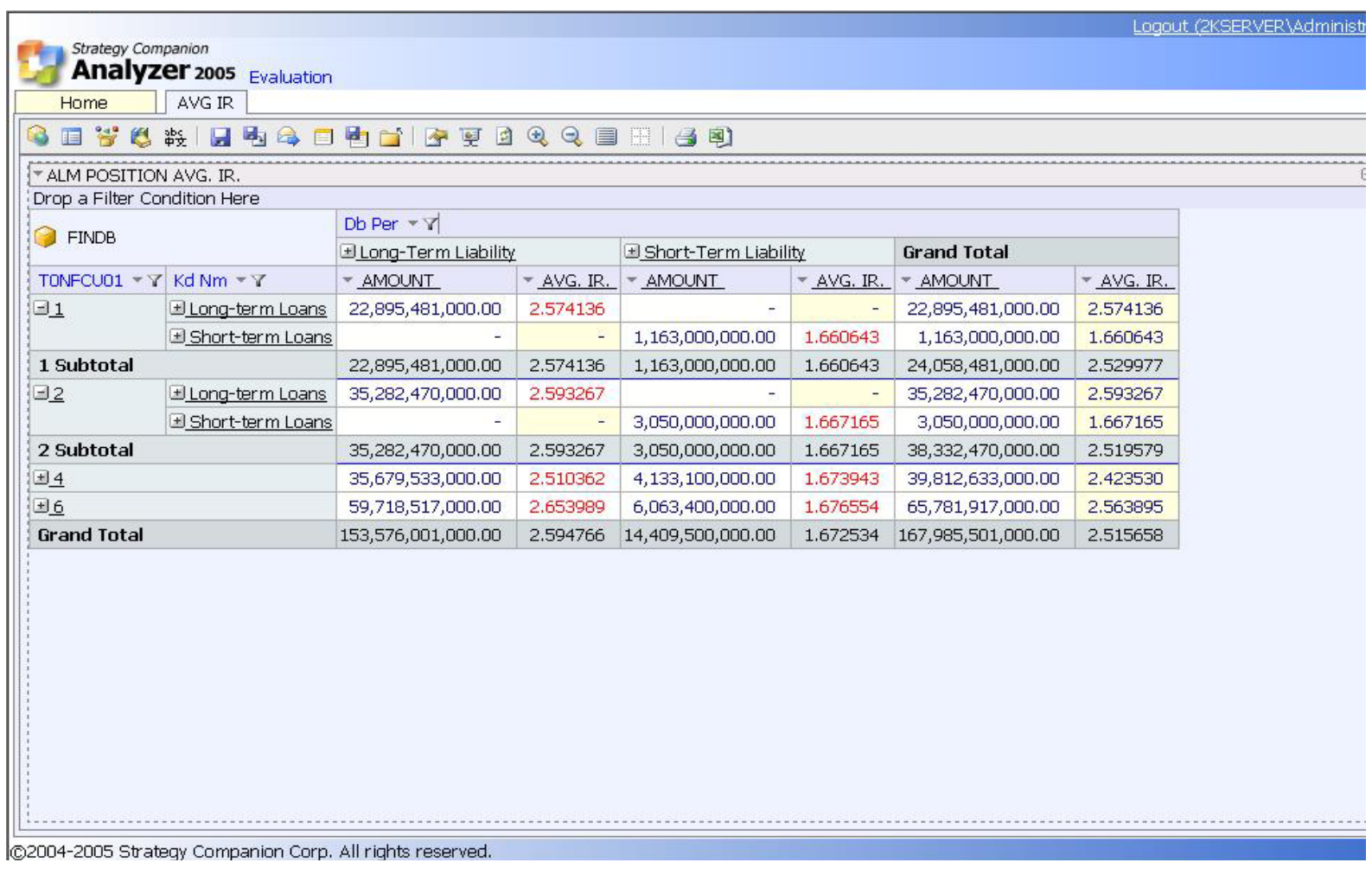

Figure 8 Liability Position and Average Interest Rate

\section{Each Period's Financial Assets and Liabilities Positions}

In order for the fund dispatching department to appropriately control each financial asset and liability position that will be expired in the future period, adding the time dimension (as shown in Figure 11) allows users of the system to control the status of future funds and draw up the necessary response strategies with the reference of overall economy situation as well as by judging potential future market changes. If it is assumed that there might be an appreciation of US dollar in near future, then it is necessary to have countermeasure on the liability position of US currency. Thus, the fund dispatching personnel could perform a risk hedging against liabilities position, which will be expired in future period, to prevent the company from the loss resulted from the exchange rate risk. 


\begin{tabular}{|c|c|c|c|c|c|c|c|c|}
\hline \multicolumn{5}{|c|}{$\begin{array}{l}\text { 14. Strategy Companion } \\
\text { Analyzer } 2005 \text { Evaluation }\end{array}$} & \multicolumn{4}{|c|}{ Logout (2KSERVERVAdministrator) Help } \\
\hline Home & \multicolumn{4}{|c|}{ AVG EXR } & \multicolumn{4}{|r|}{ 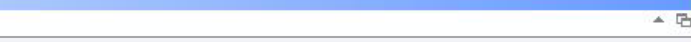 } \\
\hline \multicolumn{9}{|c|}{ 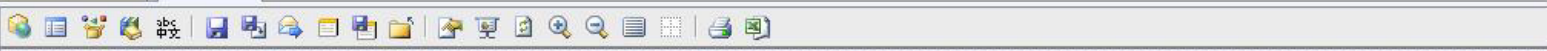 } \\
\hline \multicolumn{5}{|c|}{ ALM POSITION } & & & & ⿶大口x \\
\hline \multicolumn{9}{|c|}{ Drop a Filter Condition Here } \\
\hline \multirow{3}{*}{\multicolumn{2}{|c|}{ FINDB }} & \multicolumn{7}{|l|}{ Db Per - $\mid$ Cucy $~-\nabla \mid$} \\
\hline & & \multirow{2}{*}{\multicolumn{3}{|c|}{$\exists$ Long-Term Liability }} & \multirow{2}{*}{\multicolumn{3}{|c|}{ Long-Term Liability Subtotal }} & \multirow{2}{*}{ Grand Total } \\
\hline & & & & & & & & \\
\hline TONFCU01 - & $K d N m-\nabla$ & Foreign Currency Amount & TWD Amount & AVG. EXR. & Foreign Currency Amount & TWD Amount & AVG. EXR. & Foreign Curre \\
\hline$\square \underline{1}$ & Long-term Loans & $126,500,000.00$ & $4,167,692,000$ & 32.9462 & $126,500,000.00$ & $4,167,692,000$ & 32.9462 & 126 \\
\hline \multicolumn{2}{|l|}{1 Subtotal } & $126,500,000.00$ & $4,167,692,000$ & 32.9462 & $126,500,000.00$ & $4,167,692,000$ & 32.9462 & 126 \\
\hline$\underline{2}$ & Long-term Loans & $92,620,000.00$ & $3,051,475,360$ & 32.9462 & $92,620,000.00$ & $3,051,475,360$ & 32.9462 & 92 \\
\hline \multicolumn{2}{|l|}{2 Subtotal } & $92,620,000.00$ & $3,051,475,360$ & 32.9462 & $92,620,000.00$ & $3,051,475,360$ & 32.9462 & 92 \\
\hline$\exists \underline{4}$ & Long-term Loans & $135,300,000.00$ & $4,457,618,400$ & 32.9462 & $135,300,000.00$ & $4,457,618,400$ & 32.9462 & 135 \\
\hline \multicolumn{2}{|c|}{4 Subtotal } & $135,300,000.00$ & $4,457,618,400$ & 32.9462 & $135,300,000.00$ & $4,457,618,400$ & 32.9462 & 135 \\
\hline$\exists \underline{6}$ & Long-term Loans & $553,000,000.00$ & $18,223,451,400$ & 32.9538 & $553,000,000.00$ & $18,223,451,400$ & 32.9538 & 553 \\
\hline \multicolumn{2}{|c|}{6 Subtotal } & $553,000,000.00$ & $18,223,451,400$ & 32.9538 & $553,000,000.00$ & $18,223,451,400$ & 32.9538 & 553 \\
\hline$\underline{\mathrm{CCY}}$ & Long-term Loans & $761,000,000.00$ & $25,095,120,000$ & 32.9765 & $761,000,000.00$ & $25,095,120,000$ & 32.9765 & 761 \\
\hline \multicolumn{2}{|l|}{ CY Subtotal } & $761,000,000.00$ & $25,095,120,000$ & 32.9765 & $761,000,000.00$ & $25,095,120,000$ & 32.9765 & 761 \\
\hline \multicolumn{2}{|l|}{$\underline{\mathrm{RV}}$} & $116,000,000.00$ & $3,817,328,000$ & 32.9080 & $116,000,000,00$ & $3,817,328,000$ & 32.9080 & 116 \\
\hline \multicolumn{2}{|l|}{ Grand Total } & $1,784,420,000.00$ & $58,812,685,160$ & 32.9590 & $1,784,420,000.00$ & $58,812,685,160$ & 32.9590 & 1,784 \\
\hline 4 & & & & & & & & 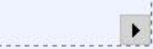 \\
\hline
\end{tabular}

Figure 9 The Position Data and Average Exchange Rate

\begin{tabular}{|c|c|c|c|c|c|c|}
\hline \multicolumn{5}{|c|}{$\begin{array}{l}\text { Aftrategy Companion } \\
\text { Analyzer } 2005 \text { Evaluation }\end{array}$} & \multicolumn{2}{|c|}{ Logout (2KSERVER YAdmir } \\
\hline \multicolumn{7}{|c|}{\begin{tabular}{|l} 
TIME POSITIONS \\
\end{tabular}} \\
\hline \multicolumn{7}{|c|}{ 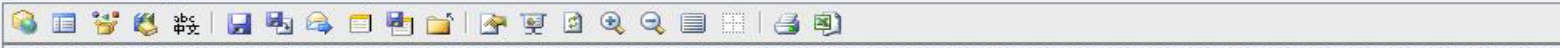 } \\
\hline \multicolumn{7}{|c|}{ TIME DEPOSIT POSITION } \\
\hline \multicolumn{7}{|c|}{ Drop a Filter Condition Here } \\
\hline \multirow{4}{*}{ FINDB } & \multicolumn{6}{|l|}{ Db Per $-\nabla|K d N m-\nabla|$ Cucy -1} \\
\hline & \multicolumn{6}{|l|}{$\exists$ Short-Term Asset } \\
\hline & \multicolumn{4}{|l|}{$\exists$ Time Deposit } & \multirow{2}{*}{\multicolumn{2}{|c|}{ Time Deposit Subtotal }} \\
\hline & \multicolumn{2}{|l|}{ TWD } & \multicolumn{2}{|l|}{ USD } & & \\
\hline TONFCU01 - & Foreign Currency Amount & TWD AMOUNT & Foreign Currency Amount & TWD AMOUNT & Foreign Currency Amount & TWD AMOUNT \\
\hline 1 & $14,237,635.00$ & $14,237,635$ & $65,021,140.01$ & $2,134,839,090$ & $79,258,775.01$ & $2,149,076,725$ \\
\hline 2 & - & - & $105,029,040.01$ & $3,448,418,471$ & $105,029,040.01$ & $3,448,418,471$ \\
\hline 4 & - & - & $32,025,392.00$ & $1,051,489,696$ & $32,025,392.00$ & $1,051,489,696$ \\
\hline 6 & $5,150,000.00$ & $5,150,000$ & $57,000,000.00$ & $1,871,481,000$ & $62,150,000.00$ & $1,876,631,000$ \\
\hline AG & $500,000.00$ & 500,000 & - & - & $500,000.00$ & 500,000 \\
\hline c & - & - & $195,079,267.50$ & $6,405,037,589$ & $195,079,267.50$ & $6,405,037,589$ \\
\hline $\mathrm{C} 1$ & $600,000.00$ & 600,000 & - & - & $600,000.00$ & 600,000 \\
\hline $\mathrm{C} 2$ & $19,250,000.00$ & $19,250,000$ & - & - & $19,250,000.00$ & $19,250,000$ \\
\hline $\mathrm{CB}$ & $21,500,000.00$ & $21,500,000$ & - & - & $21,500,000.00$ & $21,500,000$ \\
\hline $\mathrm{CY}$ & - & - & $375,777,567.94$ & $12,337,904,886$ & $375,777,567.94$ & $12,337,904,886$ \\
\hline D & $1,901,191,333.00$ & $1,901,191,333$ & - & - & $1,901,191,333.00$ & $1,901,191,333$ \\
\hline E & $720,000,000.00$ & $720,000,000$ & - & - & $720,000,000.00$ & $720,000,000$ \\
\hline $\mathrm{F}$ & $436,000,000.00$ & $436,000,000$ & - & - & $436,000,000.00$ & $436,000,000$ \\
\hline G & $38,512,552.00$ & $38,512,552$ & - & - & $38,512,552.00$ & $38,512,552$ \\
\hline I & $20,000,000.00$ & $20,000,000$ & - & - & $20,000,000.00$ & $20,000,000$ \\
\hline k & 1.128.7ก3.กก & $1.128 .7 n 3$ & - & - & 1.128.7ก.3.กก & $1.128 .7 \cap .3$ \\
\hline
\end{tabular}

\section{Figure 10 Time Deposit Position}




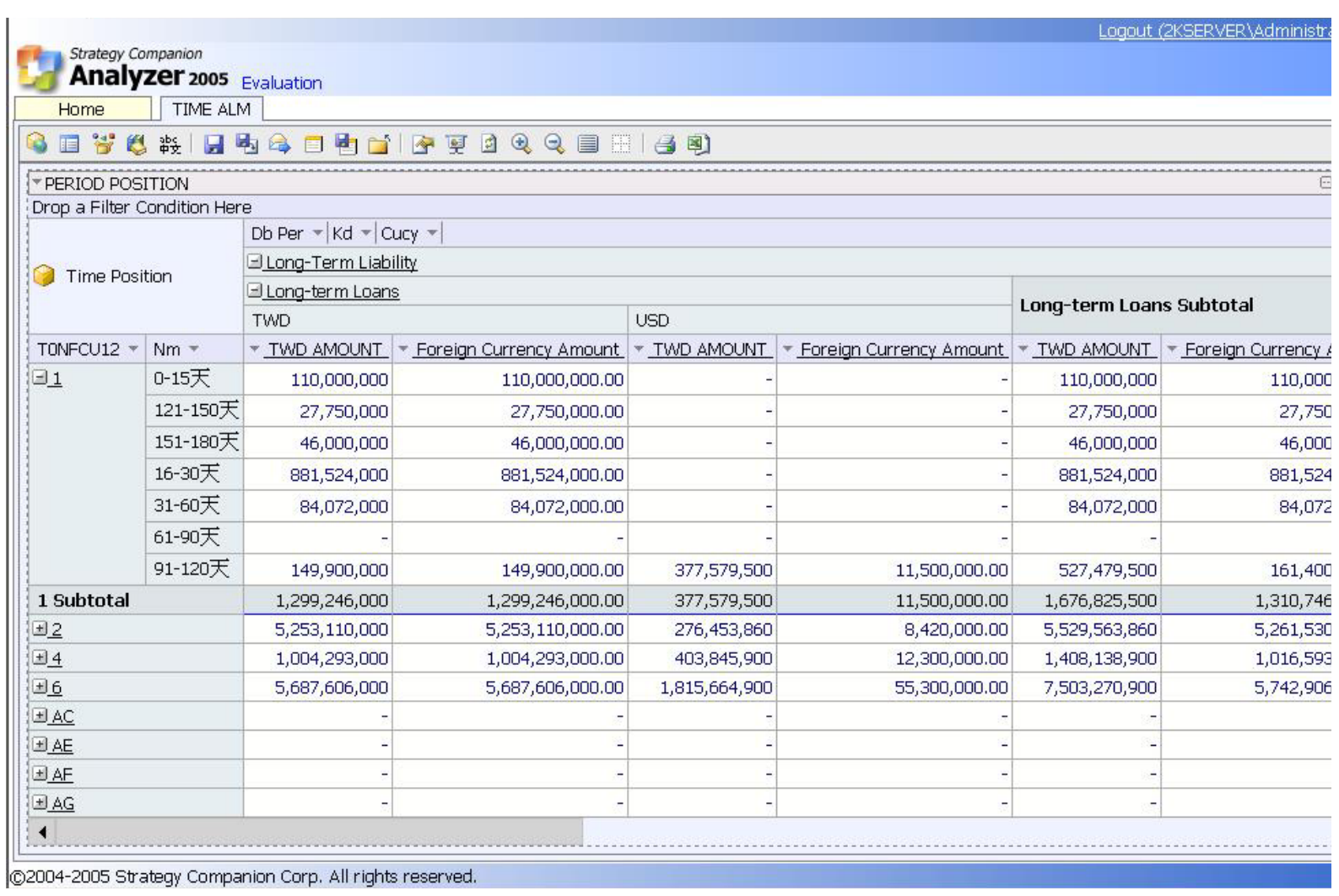

Figure 11 Each Period's Financial Assets and Liabilities Position

\section{CONCLUSION}

In the case business group of this study, all the usual operational funds is allocated in unification by the financial department; therefore the fund dispatching personnel in this department are required to control the information related to at least more than one company, namely all the financial assets and liabilities of several companies must be taken care of simultaneously. This study has accomplished the goal to develop a financial assets and liabilities DSS/BI system for the enterprise that all the ERP data needed by the financial department are extracted, transformed and loaded into the established data warehouse and OLAP analyzed. After its introduction to the case enterprise and the current system evaluation, the contributions of this study are summarized below:

- Providing dynamic data of financial asset and liability positions for the fund dispatching personnel to have a fine control of the position status all the time, as well as providing drill-down and roll-up functions for the fund dispatching personnel to clarify the aggregated or detailed position data, as a basis of fund dispatching operations, based on the company or asset and liability view. 
- Providing warning capability to remind the fund dispatching personnel to respond in advance the status of market interest rate and foreign exchange rate, and draw up a risk hedging strategy.

- Providing graphical charts and tables presentation function that allows relevant users to find out the proportion of each company's financial assets and liabilities position to that of the entire enterprise, and do the adjustment if necessary.

- Designing the receivable and payable cash gap model that helps fund dispatching people grasp future cash position status, in order to draft a strategy earlier to avoid higher funds cost when ad hoc fund needs occur.

\section{REFERENCES}

Cheng, T.-W. (2004). Intermediate Accounting, Volume I (8th ed.). Taipei, Taiwan: Wiley Publishing, Inc.

Hung, Y. F. (2001). An Application of System Dynamics Approach on Commercial Bank's Asset and Liability Management. Unpublished master thesis, National Taiwan University of Science and Technology, Taipei, Taiwan.

Inmon, W. H. (2005). Building the Data Warehouse (4th ed.). Indianapolis, IN: Wiley Publishing, Inc.

Kimball, R., Reeves, L., Ross, M., \& Thornthwaite, W. (1998). The Data Warehouse Lifecycle Toolkit: Expert Methods for Designing, Developing, and Deploying Data Warehouses. Indianapolis, IN: Wiley Publishing, Inc.

KPMG International. (2004). Financial Instruments Accounting. IFRS Reporting, UK: KPMG International.

Liang, T.-P. (2006). Decision Support Systems and Business Intelligence (2nd ed.). Taipei, Taiwan: Best-Wise Publishing Co., Ltd.

Lin, Y.-F. (2005). The current development status of global business intelligence market. Taipei, Taiwan: Market Intelligence Center, the Institute for Information Industry.

Liu, C.-L. (2003). A Planning Decision Support System for Banks’ Asset and Liability Management. Unpublished master thesis, National Kaohsiung First University of Science and Technology, Kaohsiung, Taiwan.

Mundy, J., Thornthwaite, W., \& Kimball, R. (2006). The Microsoft Data Warehouse Toolkit: With SQL Server 2005 and the Microsoft Business Intelligence Toolset. Indianapolis, IN: Wiley Publishing, Inc. 
Peng, S.-P. (1994). A Study of the Asset/Liability Management Information System in Banking Industry. Unpublished master thesis, Tamkang University, Taipei, Taiwan.

Ponniah, P. (2001). Data Warehousing Fundamentals: A Comprehensive Guide for IT Professionals. Canada: John Wiley \& Sons, Inc.

Shieh, C.-P. 2006. Financial Management: New Concepts with Unique Domestic Examples (4th ed.). Taipei, Taiwan: Best-Wise Publishing Co., Ltd.

Turban, E., Aronson, J. E., \& Liang, T.-P. (2005). Decision Support Systems and Intelligent Systems (7th ed.). Upper Saddle River, NJ: Pearson Education, Inc. 
